\title{
The Design and Implementation of Distance Network Management System under the Support of Computer
}

\author{
Lifang $\mathrm{Lu}^{1, \mathrm{a}}$, Liping $\mathrm{GaO}^{2, \mathrm{~b}}$ \\ 1,2 Yunnan Physical Education College of Qujing Normal University, china \\ a molifangfei@126.com, ${ }^{\text {b } 176288793 @ q q . c o m ~}$
}

Keywords: Modern distance education, Computer network, Design and Implementation

\begin{abstract}
With the development of multimedia technology and network communication technology, distance computer management as a kind of new management means constantly developing based on internet, attracts more and more attention. Computer distance management is a kind of activities refers to the use of multimedia technology and network communication technology carried out under the network environment. It has incomparable advantages compared to traditional management modes and creates a new kind of management mode; break traditional management mode, adopting the advanced management means and management methods, greatly improving the management efficiency.
\end{abstract}

\section{Introduce}

Based on the basic model server (B/S) system can design distance management system, require and analysis model with unified modeling language, respectively, using class diagram and sequence diagram represent system static model and dynamic model. At the same time, establish a reasonable database system, in the design of relational database, ER diagram and the corresponding relationship model was used to represent. The design and development by integration, and under the condition of existing distance education technology, such as teachers, learners and courseware information organic union, formed a relatively complete, practical distance education system.

\section{The definition of network education}

Network education is one of the adult education, refers to the management mode use TV and the Internet and other media. It broke through the boundaries of time and space, and different from the traditional management mode that students sitting in the classroom. Students can also learn through television and radio, Internet, guidance line, class research club and so on.

\section{The development of distance education in China}

The first generation is correspondence education, this way has trained many talented people for our country, but correspondence education has great limitations.

The second generation is distance education of broadcasting television education, this kind of distance education and the central TV University enjoys a high reputation in the world.

The third generation is the modern distance education network. In the $1980 \mathrm{~s}$, the emergence of the Internet, people transmit management content through the computer network. Students visit management information, receive or directly transmit courseware through the Internet web

\section{The characteristics of the distance education}

(1) openness. The modern distance education take Internet and multimedia technology as the main medium breaks the limitation of space and time. Modern distance has the characteristics of openness. Modern distance education is not subject to regional restrictions, provides a long-distance synchronous management between teachers and students, management contents, management methods and education object is open, the learner is not restricted by occupation, region. 
(2) Flexibility. One of the characteristics of modern distance education mainly based on students' self-study is prior, teacher student is complementary. It can meet the requirements of personal learning, giving educates the greater autonomy. It has changed the traditional way of management, the educators can choose their own learning way.

(3) Advanced technology. The realization of the distance education relies on the advanced technical support. The support of the modern distance education is computer technology, software technology and modern network communication technology. d digitalization and networking are the main technical characteristics of modern distance education.

(4) Resources sharing. Modern distance education provides learners with a variety of information by using various network, realizing the optimization and share of the various education resources, broking the regional and attributes of resources, can make use of superior resources such as talent, technology, curriculum integration, equipment advantages, at the same time, helping more people get a higher level of education, increasing the service efficiency of education resources, reduce the learning cost.

\section{Distance management system design and implementation based on B/S}

Browser/server mode (B/s mode) is often used in design of distance network management system mode of operation, compared to client/server model, B/s model has more prominent advantages in the process of application: the first, in the data system, using a Web browser as a client, can use a set of client programs, thereby significantly reducing development effort; The second, B/S client only need to install the browser; The third, system upgrade is easy, the purpose by the server upgrade; the fourth, Web can be used to make the interface of different systems have a common display format, greatly reduce the training cost of users .And $\mathrm{B} / \mathrm{S}$ mode is suitable for online information releasethe distance education. From the above analysis you can see and comparison of $\mathrm{B} / \mathrm{S}$ mode operation of the system has the outstanding advantages. Therefore, during the design of the distance management system browser/server mode is the best choice.

\section{Structure of B/S mode}

The front is the client browser, such as IE or Netscape, interlayer is Web server, back-end is the interface connect database server, Web server and the database server. This interface mostly uses the common gateway interface CGI technology, but because of when CGI visit database need to open and close the CGI every time. So, CGI programs run slower, easy to cause the bottleneck of the network. Now the ISAP and NSAPI technology can greatly improve the performance of the CGI program. But compared with the APS technology, they are slightly inferior. APS (active Server Pages) founded by Microsoft company, can produce dynamic and interactive Pages, belong to the ActiveX technology in the Server side

\section{The structure of system}

Distance management system under the Web server connect to the web server through the APS and client with standard internet browser, its system structure as shown in figure 1.It can be divided into three subsystems from the system structure of logically,the function are as follows:

(1) The user interface subsystem. Subsystem allows the user to visit the system data and add new database, it is the "top" of other subsystem, provide users with information and support, implement the data retrieval and insert of information.

(2) The application objects subsystem. Subsystem is placed in the Web server, mainly responsible for completing the management of courseware and the auxiliary management.

(3) The subsystems of the database. This Subsystem provides services and completes the data storage and management. 


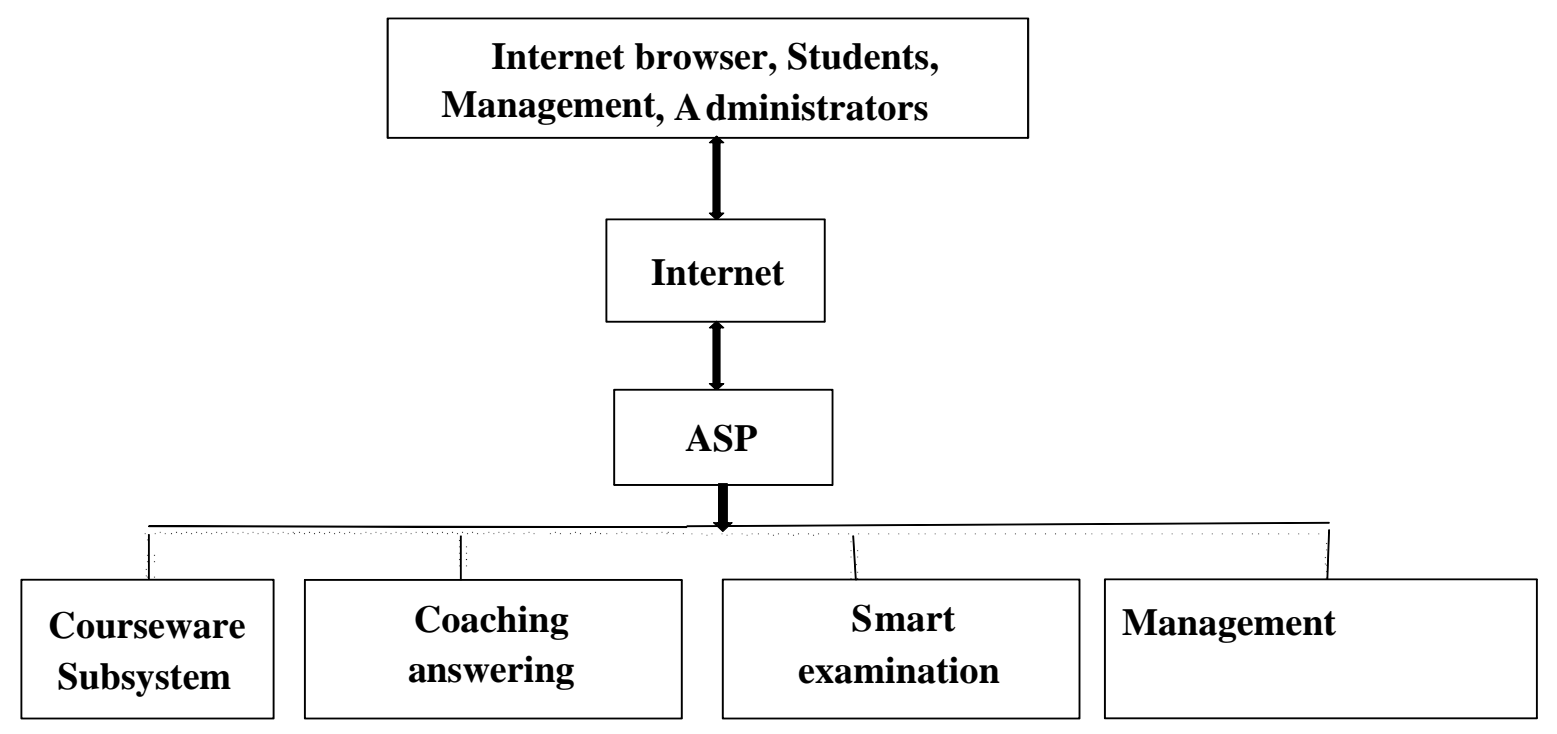

Fig1. System structure

\section{The specific implementation process}

Step 1: establish project. Web Project wizard running in visual Inter Dew can create a new developer studio workspace project file, project is automatically placed a file called global-asp and folder called images. Global-asp in charge of storing the whole application used in the global Settings, images include all kinds of graphics in the page to display.

Step 2: database connection. If you want to operate the data you must establish a connection to it. Through Visual InterDev can create a simple user interface on order to connection to the database on the network server.

Step 3: access to data via visual InterDev. After the successes connection to database, you can carry out the data in the database. Data command controls can easily complete the operation. After inserting new data command control to the project, will appear the ActiveX control properties dialog box. There you can choose appropriate data connection, at the same time, can also construct SQL statements.Just as shown in figure 2.

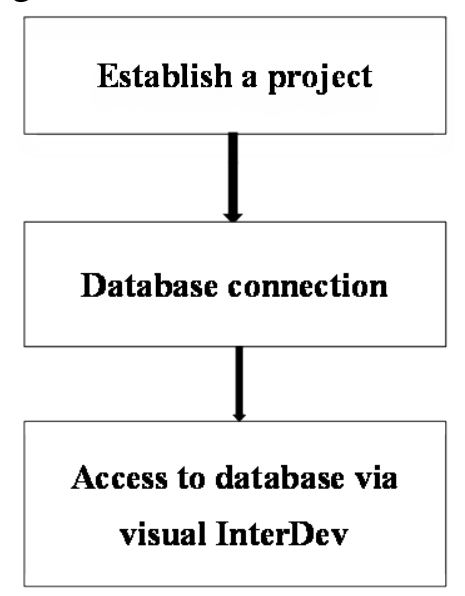

Fig2.The specific implementation process

\section{Conclusions}

This chapter analyzes the operation mode of the distance management system, takes the Web browser/server (B/S) as the basic model to design the distance management system, as well as analyzed the structure of B/S mode and the APS technology, and established the distance 
management system is installed in the Web server and connect to the Web server through the APS.

The development of science and technology will promote the development of society, the development of the society have asked people to constantly self-learning, modern distance education is inevitable trend during human society development. It will change the original human values and the conception of life style.It will depend on the advanced education technology shake off the yoke of the traditional education and contribute to people's constantly development.

\section{References}

[1] JunhongXiao.AsynchronousInteraction Patterns Research Based on BBS Platform of Living. Opening Learning,2005,(9):37_1

[2] Bill Even, Scott Hanselman, Farhan Muhammadetal. Professional ASRNET2.0[Ml. Indiana polis, Indiana:WileyPublishing,2006.183-298

[3] RobinMason,Models ofOnlineCourses,ALNMagazine, Volume2,ssueZ, Oetober1998

[4] J.5.Rosensehein, Rational Interaction:Cooperationamong IntelligentAgent 